\title{
Annexin A2 expression and phosphorylation are up-regulated in hepatocellular carcinoma
}

\author{
HAMDY SAAD MOHAMMAD ${ }^{1,5}$, KAZUTAKA KUROKOHCHI ${ }^{1}$, HIROHITO YONEYAMA ${ }^{1}$, MASAAKI TOKUDA ${ }^{2}$, \\ ASAHIRO MORISHITA ${ }^{1}$, GONG JIAN ${ }^{1}$, LIU SHI ${ }^{1}$, MASAYUKI MUROTA ${ }^{1}$, JOJI TANI ${ }^{1}$, KIYOHITO KATO ${ }^{1}$, \\ HISAAKI MIYOSHI ${ }^{1}$, AKIHIRO DEGUCHI ${ }^{1}$, TAKASHI HIMOTO ${ }^{1}$, HISASHI USUKI ${ }^{3}$, HISAO WAKABAYASHI $^{3}$, \\ KUNIHIKO IZUISHI $^{3}$, YASUYUKI SUZUKI ${ }^{3}$, HISAKAZU IWAMA ${ }^{4}$, KAZUSHI DEGUCHI ${ }^{1}$, NAOHITO UCHIDA ${ }^{1}$, \\ EMAN A. SABET ${ }^{5}$, USAMA A. ARAFA ${ }^{5}$, ALI T.A.HASSAN ${ }^{5}$, ADEL A. EL-SAYED ${ }^{5}$ and TSUTOMU MASAKI ${ }^{1}$
}

\author{
Departments of ${ }^{1}$ Gastroenterology and Neurology, ${ }^{2}$ Cell Physiology, ${ }^{3}$ Gastroenterological Surgery, \\ ${ }^{4}$ Information Technology Center, Kagawa Medical University School of Medicine, 1750-1 Ikenobe, \\ Miki-cho, Kita-gun, Kagawa 761-0793, Japan; ${ }^{5}$ Department of Internal Medicine, \\ Sohag Faculty of Medicine, Sohag University, 82534, Egypt
}

Received June 30, 2008; Accepted September 15, 2008

DOI: 10.3892/ijo_00000105

\begin{abstract}
Annexins (ANXs) constitute a family of $\mathrm{Ca}^{2+}-$ dependent membrane-binding proteins; at least 20 of them have been described to date. Among these, Annexin A2 (ANXA2) has been revealed as a multi-functional protein in vitro. Its actual role in vivo, however, requires further investigation. We already reported that ANX-I (ANXA1) was up-regulated in hepatocellular carcinoma (HCC). The role of ANXA2 in various liver diseases including HCC remains obscure. In the present study, the protein and mRNA levels of ANXA2, as well as its localization, were determined for the normal human liver, chronic hepatitis liver, and non-tumorous and tumorous portions of HCC tissues. ANXA2 was rarely detected in either normal or chronic hepatitis liver tissues, whereas it was overexpressed at both the transcriptional and translational levels in tumorous and non-tumorous regions of HCC. In addition, in many cases, more ANXA2 was expressed in the tumorous portion than in the non-tumorous portion of HCC. The expression of ANXA2 was mainly localized in cancer cells, especially in poorly differentiated HCC. Furthermore, ANXA2 was tyrosine-phosphorylated in HCC. These data suggest that overexpression and tyrosine phosphorylation of ANXA2 play important roles in the malignant transformation process leading to $\mathrm{HCC}$ and are related to the histological grade of HCC.
\end{abstract}

Correspondence to: Dr Tsutomu Masaki, Department of Gastroenterology and Neurology, Kagawa University School of Medicine, 1750-1 Ikenobe, Miki-cho, Kita-gun, Kagawa 761-0793, Japan E-mail:tmasaki@kms.ac.jp

Key words: hepatocellular carcinoma, ANXA2, phosphorylation

\section{Introduction}

Annexins (ANXs) constitute a family of $\mathrm{Ca}^{2+}$-dependent phospholipid-binding proteins with various membrane-related functions $(1,2)$. At least 20 members of the Annexin family have been described to date (3). The proteins included in this family are lipocortins $(4,5)$, calpactins $(6,7)$, calelectrins $(8-10)$, calcimedins (11), anticoagulant proteins (12), endonexins (13), macrocortin $(14,15)$, and chromobindins (16). ANXs were first described as glucocorticoid-inducible inhibitory proteins of phospholipase A2 $(14,15)$. These proteins have a unique $\mathrm{N}$-terminal tail that is variable in length and sequence (17). ANXA2, also called Annexin II, is one of the best characterized of the group of ANXs (18). ANXA2 among ANXs is cleaved by chymotrypsin into a $33-\mathrm{kDa}$ C-terminal core domain and 3-kDa N-terminal domain of 30 amino acids (19). The N-terminal domain of ANXA2 is a major substrate for phosphorylation by retroviral tyrosine-specific kinase $\left(\right.$ pp60 $\left.0^{\mathrm{v}-\mathrm{src}}\right)$ (20). Residues of Tyr 23 and serines 11 and 25 are phosphorylated in cells by c-Src and PKC, respectively (21), after activation of insulin receptor (22), insulin growth factor regulator (23), or platelet-derived growth factor-R (24). Therefore, ANXA2 may play a role as a second messenger for transduction of the growth, differentiation and transformation (3).

The role of ANXA2 in cellular transformation was first suggested by the identification of ANXA2 as the oncogene product $\mathrm{V}$-src phosphorylation substrate in transformed fibroblasts (25). Subsequently, ANXA2 expression has been found to be up-regulated in several types of spontaneous neoplasms such as pancreatic cancer (26), gastric cancer (27), colorectal cancer (28) and high-grade glioma (29). On the other hand, its expression was down-regulated in prostate (30-32) and esophageal (33) cancer and in head and neck dysplasia and squamous cell carcinoma $(34,35)$. In our previous report, ANXA2 was increased in proliferative or regenerative hepatocytes, suggesting that this protein plays a certain 
role in the proliferation events of normal hepatocytes (36). However, its expression in cases of liver disease, including hepatocellular carcinoma (HCC), is not well known. Therefore, we analyzed the amount of ANXA2 at the protein and messenger RNA (mRNA) levels, as well as its localization in various liver tissues including HCC. We also investigated the relationship between ANXA2 expression and histological grade of HCC. In addition, we compared the tyrosine phosphorylation of ANXA2 in HCC with that in non-tumorous liver cirrhosis.

\section{Patients and methods}

Patients. Between 1997 and 2007, liver biopsy specimens were obtained from 39 patients with chronic hepatitis $(\mathrm{CH})$ and 34 patients with HCC at Kagawa Medical University. Of those patients with $\mathrm{CH}, 31$ patients were positive for $\mathrm{HCV}$ RNA, and others were positive for HBsAg. Seven patients were in F1, 9 patients in F2, 11 patients in F3, and 12 patients in F4 according to Desmet's classification (37). The mean age of the patients was $50.9 \pm 13.4$ (mean $\pm \mathrm{SD}$; range 21-80). HCC specimens were obtained from 6 patients by surgical resection and the others were obtained by needle biopsy before therapy. Twenty-eight patients were males, and 6 were females. The mean age of the patients was $64.5 \pm 9.3$ (mean $\pm \mathrm{SD}$; range 34-84 years). Thirty patients with HCC were positive for HCV-RNA, and 4 patients with $\mathrm{HCC}$ were positive for HBsAg. The histological grade of HCC was determined as well, moderately or poorly differentiated according to the criteria of the International Working Party (38). The numbers of patients with well, moderately and poorly differentiated HCCs were 4, 22 and 8, respectively. Five normal liver (NL) samples (4 males and 1 female; mean age 60.2 \pm 4.1 years; range 56-67 years) were obtained during surgery for colon cancer with liver metastasis. These patients were negative for both HCV-RNA and HBsAg. Informed consent was obtained from each patient prior to participation.

Chemicals. The monoclonal antibody against ANXA2 was purchased from Nippon Shinyaku Co., Ltd. (Tokyo, Japan). An anti-phosphotyrosine monoclonal antibody was purchased from Upstate Biotechnology Co., Ltd. (Tokyo, Japan). The monoclonal antibody (clone $\operatorname{IgG} 2 \mathrm{b \kappa}$ ) was produced in vitro by the mouse-mouse hybridoma, 4G10. This antibody reacts to phosphotyrosinated proteins, but not with those containing phosphoserine or phosphothreonine. Other chemicals were purchased from Sigma Chemical Co. (Tokyo, Japan) or Wako Pure Chemical Co. (Tokyo, Japan).

Gel electrophoresis and Western blot analysis. SDS (sodium dodecyl sulfate)-PAGE (polyacrylamide gel electrophoresis) was performed according to the method of Laemmli (39). Western blot analysis was performed according to the method of Towbin et al (40) using a mouse monoclonal antibody to ANXA2 in a 1:400 dilution, and a horseradish peroxidaselinked secondary antibody. Immunoreactive proteins were visualized with an enhanced chemiluminescence detection system (Amersham Chemical Co, Tokyo, Japan) on X-ray film, as described in our previous reports (41-51).
Partial purification of ANXA2. ANXA2 was partially purified from liver tissues according to the procedure of the previous reports $(36,44)$. Tissue samples were frozen on dry-ice within 20 min of collection. The samples were homogenized in TNE buffer [10 mM Tris $\mathrm{HCl}$ (pH 7.5), $1 \mathrm{mM}$ EGTA, $150 \mathrm{mM}$ $\mathrm{NaCl}, 1 \mathrm{mM} \mathrm{Na} \mathrm{VO}_{4}, 50 \mathrm{mM} \mathrm{Na} \mathrm{MoO}_{4}, 1 \%$ Nonidet P-40 and $100 \mathrm{U} / \mathrm{ml}$ aprotinin] and centrifuged at 29,000 $\mathrm{g}$ for $15 \mathrm{~min}$ at $4^{\circ} \mathrm{C}$. The livers were washed and homogenized in $10 \mathrm{mmol} / \mathrm{l}$ dithiothreitol, $100 \mu \mathrm{g} / \mathrm{ml}$ soybean trypsin inhibitor, $1 \mu \mathrm{g} / \mathrm{ml}$ leupeptin, $1 \mathrm{mmol} / \mathrm{l}$ diisofluorophosphate, and $10 \mathrm{mmol} / \mathrm{l}$ $\mathrm{CaCl}_{2}$. After standing for $20 \mathrm{~min}$ at $4^{\circ} \mathrm{C}$, the homogenate was centrifuged for $15 \mathrm{~min}$ at $2,900 \mathrm{~g}$, then the supernatant was centrifuged for $40 \mathrm{~min}$ at $27,000 \mathrm{~g}$. The pellet was resuspended in buffer A $(100 \mathrm{nmol} / 1 \mathrm{NaCl}, 1 \mathrm{mmol} / \mathrm{l}$ dithiothreitol, $1 \mathrm{mmol} / \mathrm{C} \mathrm{CaCl}_{2}, 1 \%$ Triton X-100 and $10 \mathrm{mmol} / \mathrm{l}$ imidazole-hydrochloride, $\mathrm{pH} \mathrm{7.4),} \mathrm{stirred} \mathrm{for} 20 \mathrm{~min}$, and centrifuged at $25,000 \mathrm{~g}$ for $30 \mathrm{~min}$. The pellet was washed twice with buffer A without Triton X-100 and resuspended in buffer B (100 mmol/1 NaCl, $1 \mathrm{mmol} / \mathrm{l}$ dithiothreitol, $1 \mathrm{mmol} / \mathrm{l}$ ethylene glycol tetraacetic acid, and $10 \mathrm{mmol} / \mathrm{l}$ imidazolehydrochloride, $\mathrm{pH} 7.4$ ), then centrifuged at 100,000 $\mathrm{g}$ for $70 \mathrm{~min}$. The supernatant was extensively dialyzed against buffer C (1 mmol/l dithiothreitol, $10 \mathrm{mmol} / 1$ imidazolehydrochloride, $\mathrm{pH}$ 7.4). The fractions were subjected to SDS-PAGE and Western blotting using ANXA2 monoclonal antibody. The protein concentration in partial purification of ANXA2 was measured by the bicinchoninic acid protein assay (52).

Immunohistology for human liver tissues. We prepared 2- $\mu \mathrm{m}$ thick sections from formalin-fixed, paraffin-embedded tissue blocks. Sections of HCC tissue specimens were immunohistologically stained using the ABC method, as described in our previous reports $(52,53)$. To detect ANXA2, sections were placed in $10 \mathrm{mM}$ citrate buffer $(\mathrm{pH} 6.0)$ and processed at $500 \mathrm{~W}$ at $95^{\circ} \mathrm{C}$ for $10 \mathrm{~min}$ in a microwave oven. Sections were deparaffinized in xylene, dehydrated in a graded series of alcohol solutions, and then mixed with a solution containing $0.5 \%$ hydrogen peroxide to block endogenous peroxidase activity. After washing with phosphate-buffered saline (PBS), the sections were processed for immunostaining. Primary incubation was performed overnight at $24^{\circ} \mathrm{C}$ with the monoclonal antibody against ANXA2. Immunoreactivity products were visualized using diaminobenzidine, and the sections were counterstained with Mayer's hematoxylin. The specificity of immunostaining was examined using nonimmune mouse $\mathrm{IgG}$ as a negative control for primary antibody.

Extraction of RNA and Northern blot analysis. The total RNA fraction was extracted from the liver using acid-guanidinium thiocyanate-phenol-chloroform. The probe used for Northern blot analysis was the cDNA clone 123 , which has an open reading frame of 1,008 nucleotides and encodes a protein of 339 amino acids. This cDNA was kindly provided by Dr T. Hunter (Molecular Biology and Virology Laboratory, San Diego, CA). Total RNA isolated from liver tissues was denatured and separated by electrophoresis in formaldehyde agarose gel. RNA was transferred to a Hybond $\mathrm{N}$ membrane (Amersham, Chemical Co., Tokyo, Japan). After prehybridization at $42^{\circ} \mathrm{C}$ for $4 \mathrm{~h}$, the membranes were incubated at $42^{\circ} \mathrm{C}$ 

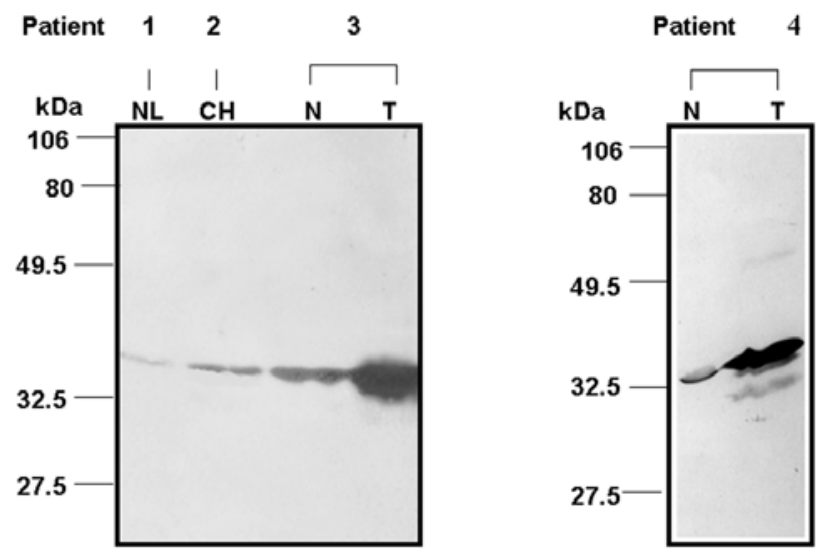

Figure 1. Western blot analysis of partially purified ANXA2 using a monoclonal antibody as a probe. Twenty micrograms of the partially purified ANXA2 fraction of tumorous $(\mathrm{T})$ and non-tumorous $(\mathrm{N})$ regions of HCC, chronic hepatitis $(\mathrm{CH})$ and normal liver (NL) tissues were subjected to SDS-PAGE and analyzed as described in Materials and methods. A highly immunoreactive ANXA2 band is seen in the T portion of hepatocellular carcinoma. The histology of the $\mathrm{N}$ portion in cases 3 and 4 is cirrhosis and chronic hepatitis, respectively.

for $15 \mathrm{~h}$ in a hybridization mixture containing $50 \%$ formamide, $5 \mathrm{X}$ standard saline citrate, $10 \mathrm{nmol} / 1$ sodium phosphate (pH 6.8), 0.5\% SDS, 5X Denhart's medium, $20 \mu \mathrm{g} / \mathrm{ml}$ salmon sperm DNA, and the $\left[{ }^{32} \mathrm{P}\right]$-labeled cDNA probe. The membranes were washed three times with $0.2 \mathrm{X}$ standard saline citrate containing $0.1 \%$ SDS for $30 \mathrm{~min}$ at $42^{\circ} \mathrm{C}$, air-dried, and exposed to Kodak X-Omat film (Eastman Kodak, Rochester, $\mathrm{NY})$ at $-70^{\circ} \mathrm{C}$.

Immunoprecipitation. Aliquots containing $50 \mu \mathrm{g}$ of the partially purified ANX fractions from HCC were incubated with $2 \mu \mathrm{l}(2 \mu \mathrm{g})$ of monoclonal phosphotyrosine antibody for $4 \mathrm{~h}$ at $4^{\circ} \mathrm{C}$. Samples were then incubated with $50 \mathrm{ml}$ of $50 \%$ (vol/vol) protein A sepharose CL-4B in buffer [20 mmol/1

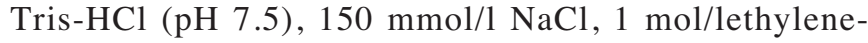
diaminetetraacetic acid, $0.02 \%$ sodium azide (wt/vol), $0.5 \%$ $\mathrm{NP} 40$, and $10 \mu \mathrm{g} / \mathrm{ml}$ bovine serum albumin]. Immunoprecipitates were washed four times in $100 \mathrm{mmol} / \mathrm{l}$ Tris- $\mathrm{HCl}$ (pH 7.5) containing $0.5 \%$ Triton $\mathrm{X}-100$, then resuspended in SDS-PAGE buffer [50 mmol/1 Tris-HCl (pH 6.8), 2\% SDS, $10 \%$ glycerol, and $0.02 \%$ bromophenol blue]. Proteins were resolved in $12.5 \%$ SDS-PAGE, and phosphorylated ANXA2 was detected by Western blotting using monoclonal ANXA2 antibody.

Densitometry. The density of the immunoreactive band of $36 \mathrm{kDa}$ for ANXA2 obtained on Western blotting using was analyzed by densitometric scanning (Tlc scanner, Shimizu, Co., Ltd., Kyoto, Japan).

Statistical analysis. The significance of the difference on Western blotting of ANXA2 was determined with the Student's t-test. Data are expressed as means $\pm \mathrm{SD}$. The quantitative variables were analyzed with the $\chi^{2}$ test to compare the relationship between ANXA2 protein expression and HCC differentiation from immunohistochemical data. The significance of the differences between observations was determined at a $\mathrm{p}<0.05$.

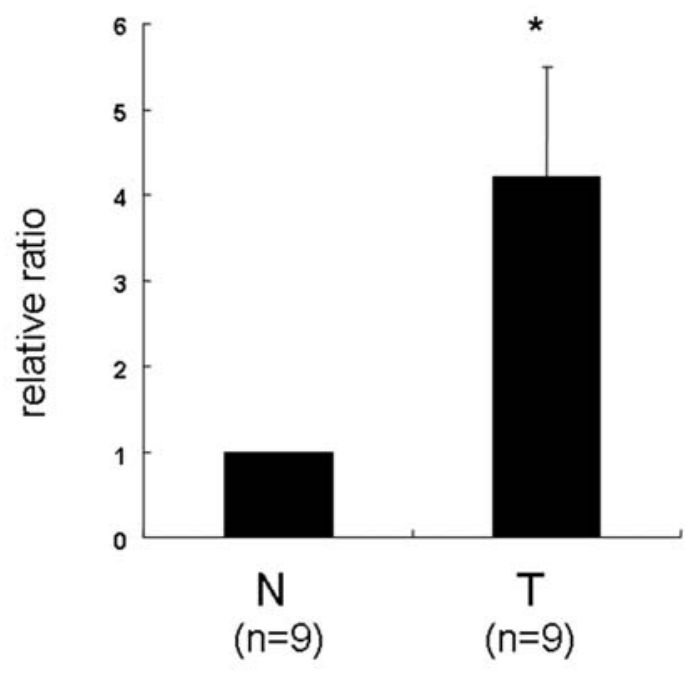

Figure 2. Densitometry of Western blot analysis of ANXA2 in tumorous (T) and non-tumorous $(\mathrm{N})$ portions of HCC. The ratio in ANXA2 band density of $\mathrm{T}$ tissues to $\mathrm{N}$ tissues was $4.2 \pm 1.3$. The $\mathrm{T}$ portions contained significantly more ANXA2 than the $\mathrm{N}$ regions $(\mathrm{P}<0.01)$

\section{Results}

Western blot analysis of AXNA2 in liver tissues obtained by surgery or biopsy. The level of ANXA2 expression was markedly increased in the primary tumorous (T) tissues compared with adjacent non-tumorous (N) tissues (Fig. 1, patients 3 and 4). The histological grades of patients 3 and 4 were moderately and poorly differentiated HCC, respectively. A very weak band was detected at $36 \mathrm{kDa}$ in normal liver (NL) (no. 1) and chronic hepatitis (CH) (no. 2) patients.

Densitometry of Western blotting for ANXA2. The density of the immunoreactive $36-\mathrm{kDa}$ band obtained by Western blotting was analyzed by means of densitometric scanning (Fig. 2). The densitometric ratio of the ANXA2 band of T tissues to $\mathrm{N}$ tissues was $4.2 \pm 1.3(\mathrm{p}<0.01)$, indicating that significantly more ANXA2 was present in the $\mathrm{T}$ parts than in the $\mathrm{N}$ regions of $\mathrm{HCC}$.

Localization of ANXA2 in NL, CH, $N$ and T portions. Expression of ANXA2 was not detected in NL (Fig. 3A, patient 1), but in $\mathrm{CH}$, staining for ANXA2 appeared only in some hepatocytes adjacent to the area with the inflammation (Fig. 3B, patient 2, arrows). In cirrhotic liver tissues with HCC, ANXA2 was expressed only in some hepatocytes along the limiting plate and at the periphery of the regenerating nodules (Fig. 3C, patient 3, arrows). ANXA2 was also immunostained in biliary epithelial cells (Fig. 3C, patient 3, arrowhead). Typical ANXA2 staining in HCC is shown in Fig. 3D (patient 3). The expression of ANXA2 in HCC was detected not only in the cytoplasm (Fig. 3D), but also in the membranes (Fig. 3D, arrows) of cancer cells. In patient 4, ANXA2 expression was not seen in $\mathrm{N}$ tissue corresponding to NL, but was stained in cancer cells (Fig. 3E, arrows). All patient numbers correspond to those in Fig. 1. In addition, all HCC tissues expressed ANXA2, and poorly differentiated tissues were more strongly positive than well differentiated tissues $(\mathrm{P}<0.01)($ Table I) 

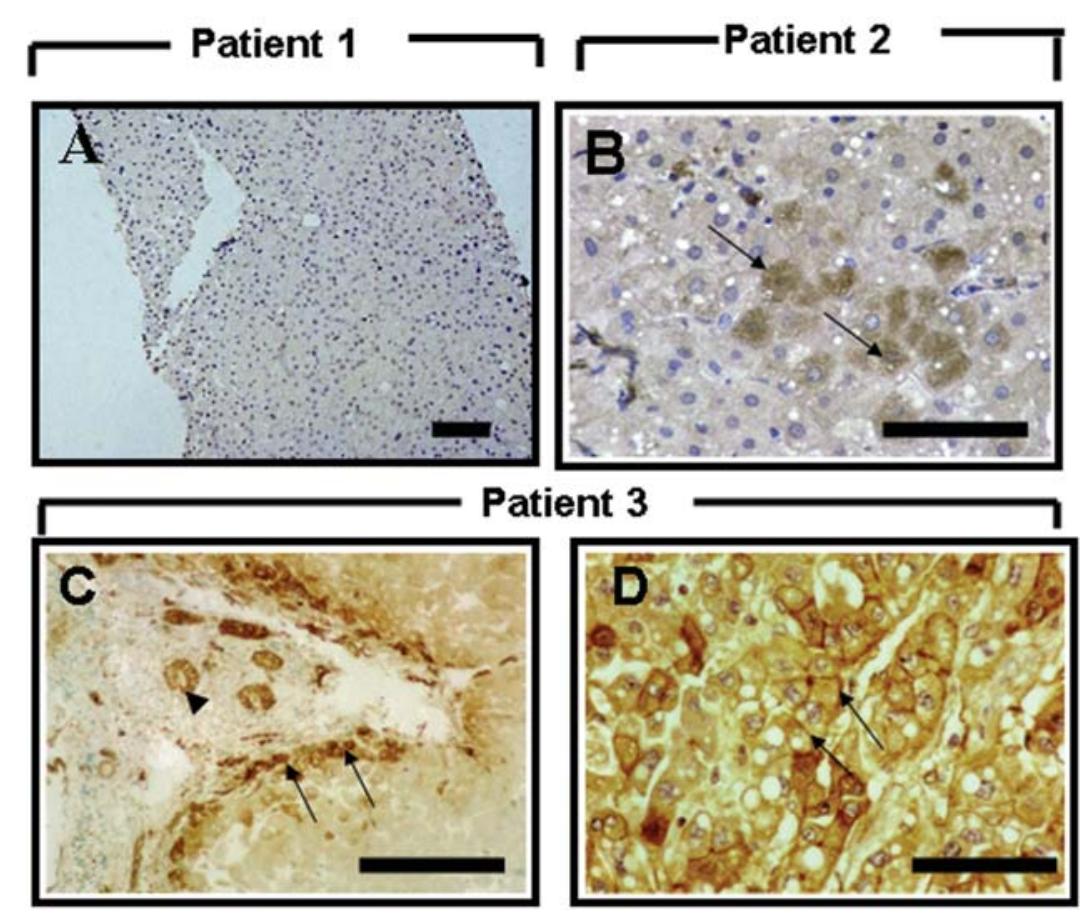

Patient 3
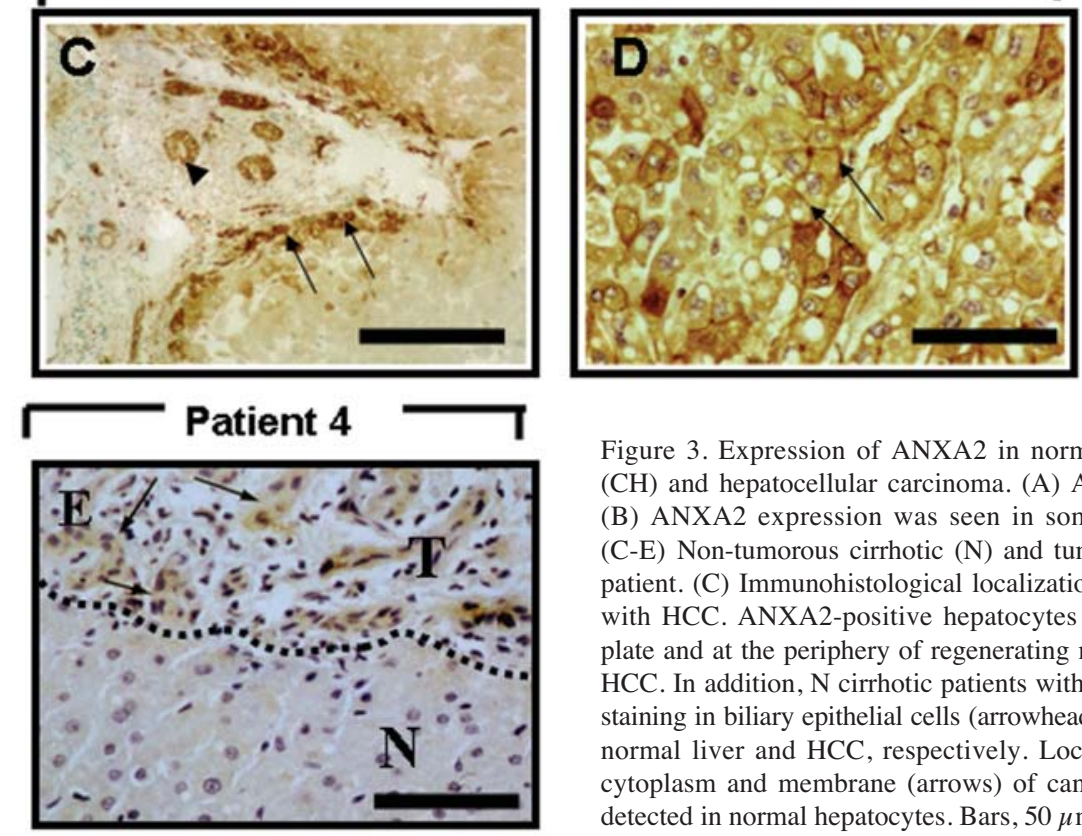

Figure 3. Expression of ANXA2 in normal liver (NL), chronic hepatitis $(\mathrm{CH})$ and hepatocellular carcinoma. (A) ANXA2 was not detected in NL. (B) ANXA2 expression was seen in some hepatocytes (arrows) in $\mathrm{CH}$. (C-E) Non-tumorous cirrhotic $(\mathrm{N})$ and tumorous tissue $(\mathrm{T})$ from the same patient. (C) Immunohistological localization of ANXA2 in cirrhotic tissues with HCC. ANXA2-positive hepatocytes were located along the limiting plate and at the periphery of regenerating nodules in $\mathrm{N}$ cirrhotic livers with HCC. In addition, N cirrhotic patients with HCC showed ANXA2 immunostaining in biliary epithelial cells (arrowhead). (D and E) ' $\mathrm{N}$ ' and ' $\mathrm{T}$ ' indicate normal liver and HCC, respectively. Localization of ANXA2 was in the cytoplasm and membrane (arrows) of cancer cells, while no staining was detected in normal hepatocytes. Bars, $50 \mu \mathrm{m}$.

Table I. Relationship between ANXA2 protein expressed and degree of HCC differentiation.

\begin{tabular}{lrrrr}
\hline & \multicolumn{4}{c}{ ANXA2 protein status } \\
\cline { 2 - 5 } & - & +1 & +2 & +3 \\
\hline Well differentiated & 0 & 4 & 0 & 0 \\
Moderately differentiated & 0 & 16 & 6 & 6 \\
Poorly differentiated & 0 & 0 & 0 & 8 \\
\hline
\end{tabular}

The staining of cancer cells in HCC specimens was studied in 34 patients with HCC. ANXA2 was correlated to the degree of differentiation of cancer cells $(\mathrm{P}<0.01)$.

Northern blotting of ANXA2 in NL, CH and N and T portions of HCC. Equal amounts of total RNA were used for NL, CH, N cirrhotic tissues, and T tissues (Fig. 4A and C). Autoradiography analysis revealed a single band of the $1.6-\mathrm{kb}$ mRNA of ANXA2 in T tissues and surrounding $\mathrm{N}$ cirrhotic tissues. More ANXA2-mRNA was expressed in $\mathrm{T}$ portions than in $\mathrm{N}$ portions (patients 3 and 4 in Fig. 4B and D), whereas it was not only undetectable in NL (patient 1 in Fig. 4B), but also in NL with HCC (patient 4 in Fig. 4). ANXA2 mRNA was also expressed at very low levels in $\mathrm{CH}$ (patient 2 in Fig. 4B). All patient numbers correspond to the numbers in Figs. 1 and 3.

Detection of tyrosine-phosphorylated ANXA2 in HCC. In one of the nine cases examined in this study, the ANXA2 levels in $\mathrm{T}$ and $\mathrm{N}$ cirrhotic tissues were similar on Western blotting (Fig. 5A). Overexpressed ANXA2 in T portion was shown to have phosphotyrosine residues by means of Western blotting using anti-phosphotyrosine monoclonal antibody (PY) (Fig. 5B). However, the ANXA2 overexpressed in N cirrhotic tissue was not tyrosine-phosphorylated (Fig. 5B).

\section{Discussion}

ANXA2 is thought to be involved in the cellular signal transduction associated with inflammation, differentiation and proliferation (3). We have already reported that ANXA2 levels increase in proliferative (or regenerative) hepatocytes suggesting that it plays a role in the proliferative events (36). Although Frohlich et al reported that ANXA2 was up-regulated in $\mathrm{HCC}$ (54), the expression in $\mathrm{CH}$ and liver cirrhosis was not clear, and the phosphorylation of ANXA2 was not 


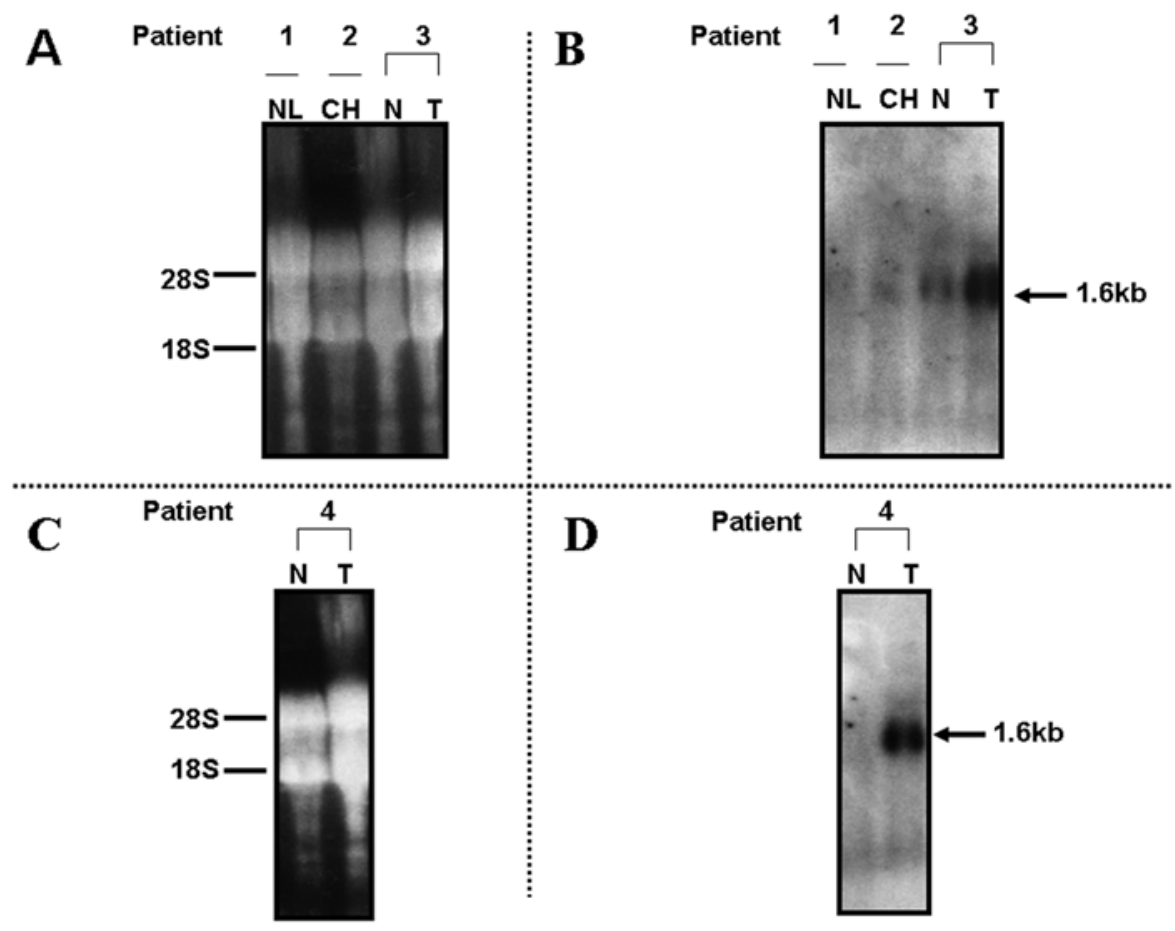

Figure 4. Northern blot analysis of ANXA2 in normal liver $(\mathrm{NL})$, chronic hepatitis $(\mathrm{CH})$, non-tumorous $(\mathrm{N})$ and tumorous $(\mathrm{T})$ portions of hepatocellular carcinoma. Patient numbers correspond to those in Fig. 1. (A and C) Twenty micrograms of total RNA was loaded in each lane, by the intensity of the bands of $28 \mathrm{~S}$ and $18 \mathrm{~S}$ ribosomal RNA in agarose gel stained with ethidium bromide and visualized under UV illumination. (B) Northern blot analysis of ANXA2 mRNA using ANXA2 cDNA as a probe. A single band of ANXA2 mRNA at $1.6 \mathrm{~kb}$ (arrows) was detected in $\mathrm{CH}$ (patient 2), non-tumorous cirrhotic tissue (N) and the tumorous portion (T) (patient 3). The expression of ANXA2 mRNA in the T portion was higher than that in the $\mathrm{N}$ portion. However, no bands were detected in $\mathrm{NL}$ (patient 1 and the $\mathrm{N}$ portion from patient 4). The histology of the non-tumorous portion in cases 3 and 4 is cirrhosis and normal tissue, respectively.
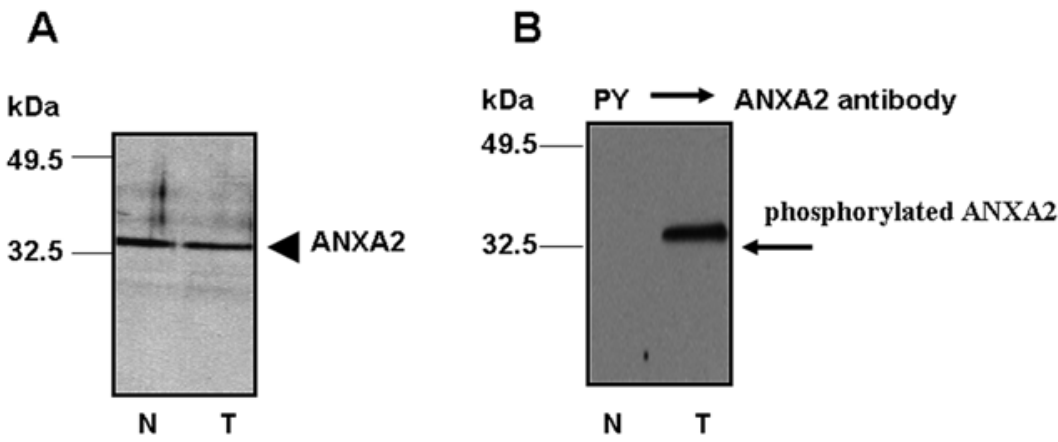

Figure 5. Tyrosine phosphorylation of ANXA2 in non-tumorous (N) and tumorous tissue (T) of HCC. (A) In one case, the ANXA2 levels in N and T tissues from the same patient were similar on Western blotting (arrowhead). (B) Western blotting of ANXA2 after immunoprecipitation using an anti-phosphotyrosine antibody (PY) in the N and T portions of HCC. The tyrosine phosphorylation of ANXA2 was detected in T portions of HCC (arrow), but not in N cirrhotic tissue.

studied. Therefore, the expression of ANXA2 in various liver diseases including HCC has not been adequately analyzed.

In this study, we showed that the expression ANXA2 was abundant in HCC and N cirrhotic tissues at both the transcript and protein levels, and that more ANXA2 was expressed in the $\mathrm{T}$ tissues than in the $\mathrm{N}$ cirrhotic tissues. On the other hand, ANXA2 was expressed at very low levels in NL and $\mathrm{CH}$ tissues. Moreover, ANXA2 was expressed more in poorly differentiated than in well and moderately differentiated HCC. We also showed that the enhanced ANXA2 in HCC was tyrosine-phosphorylated.

The levels of ANXA2 are highest in pancreas and skin tissues, intermediate in lung, colon, heart and spleen tissues, and low in muscle, kidney, stomach, esophagus and liver tissues (54). In the present study, we also showed that the protein and mRNA levels of ANXA2 were extremely low in NL and CH (Figs. 1, 3 and 4). However, the expression of ANXA2 was enhanced in and the $\mathrm{T}$ and $\mathrm{N}$ cirrhotic portion of HCC. The amount of ANXA2 in the T portion of HCC was $4.2 \pm 1.3$ times higher than that in the $\mathrm{N}$ portion (Fig. 2). These observations suggest that induction of ANXA2 is associated with a malignant transformation process leading to HCC. In previous reports, overexpression of ANXA2 has been reported in pancreatic (26), gastric (27), brain (29), breast (55), lung (56), hematologic $(57,58)$, and colonic cancer (59). Considering our data and these previous reports, the induction of ANXA2 may be related to malignant processes in various malignant tumors. 
ANXA2 is involved in cell differentiation (3). We analyzed the relationship between ANXA2 expression and the histological grades of HCC. ANXA2 staining was more intense in moderately or poorly differentiated HCC, rather than in well differentiated specimens (Table I). These data suggest that the expression of ANXA2 may also be closely related to the histological grade of HCC.

We also showed that the overexpressed ANXA2 in HCC was tyrosine-phosphorylated. The ANXA2 level in HCC was similar to $\mathrm{N}$ cirrhotic tissues in only 1 case. Interestingly, the tyrosine phosphorylation of ANXA2 was detected in HCC but not in $\mathrm{N}$ cirrhotic tissue. Hunter et al have reported that chicken cells transformed by Rous sarcoma virus exhibit up to 8-fold more tyrosine phosphorylation than uninfected cells (60). These data suggest that tyrosine phosphorylation is an important event in hepatocarcinogenesis. It has been reported that ANXA2 is an excellent substrate for Src. We have reported that the level of Src kinase activity in HCC is higher than that in $\mathrm{N}$ cirrhotic tissues (61). These data suggest that ANXA2 in HCC may be tyrosine-phosphorylated via the elevated tyrosine kinase activity of Src or other kinases, and that increased ANXA2 amounts and its tyrosine phosphorylation may be related to human hepatocarcinogenesis.

In conclusion, ANXA2 is almost undetectable in normal liver and chronic hepatitis tissues, but its synthesis is induced in transformed hepatocytes. The overexpression and tyrosine phosphorylation of ANXA2 may be among several factors that contribute to malignant transformation, progression and differentiation in HCC. Therefore, HCC may offer a novel model for studying the functions of ANXA2 in malignant transformation.

\section{Acknowledgements}

This work was supported in part by Grants-in-Aid for Scientific Research (C-19590770, B19390200) from the Ministry of Education, Culture, Sports, Science and Technology of Japan, and by the Alumni association of the Faculty of Medicine of Kagawa University.

\section{References}

1. Gerke V, Creutz CE and Moss SE: Annexins; linking $\mathrm{Ca}^{2+}$ signalling to membrane dynamics. Nat Rev Mol Cell Biol 6: 449-461, 2005.

2. Rescher U and Gerke V: Annexins; unique membrane binding proteins with diverse functions. J Cell Sci 117: 2631-2639, 2004.

3. Pomila Singh: Role of Annexin-II in GI cancers: interaction with gastrins/progastrins. Cancer Lett 252: 19-35, 2007.

4. Glenney JR: Two related but distinct forms of the Mr 36,000 tyrosine kinase substrate (calpactin) that interacts with phospholipid and actin in a $\mathrm{Ca}^{2+}$-dependent manner. Proc Natl Acad Sci USA 83: 4258-4262, 1996.

5. Saris CJ, Tack BF, Kristensen T, Glenney JR and Hunter T: The cDNA sequence for protein-tyrosine kinase substrate p36 (calpactin I heavy chain) reveals a multidomain protein with internal repeats. Cell 46: 201-212, 1986.

6. Geisow MJ, Fritsche U, Hexham JM, Dash B and Johnson T: A consensus amino- acid sequence repeat in Torpedo and mammalian $\mathrm{Ca}^{2+}$-dependent membrane-binding proteins. Nature 320: 636-638, 1986.

7. Geisow MJ, Walker JH, Boustead C and Taylor W: Localization and structure of novel calcium-regulated phospholipid-binding proteins. Biochem Soc Trans 15: 800-802, 1987.
8. Sudhof TC, Slaughter CA, Leznicki I, Barjon P and Reynolds GA: Human $67-\mathrm{kDa}$ calelectrin contains a duplication of four repeats found in 35-kDa lipocortins. Proc Natl Acad Sci USA 85: 664-668, 1988.

9. Smith VL and Dedman JR: An immunological comparison of several novel calcium-binding proteins. J Biol Chem 261: 15815-15818, 1986.

10. Funakoshi T, Hendrickson LE, McMullen BA and Fujikawa K: Primary structure of human placental anticoagulant protein. Biochemistry 26: 8087-8092, 1987.

11. Weber K, Johnsson N, Plessmann U, et al: The amino acid sequence of protein II and its phosphorylation site for protein kinase $\mathrm{C}$; the domain structure $\mathrm{Ca}^{2+}$-modulated lipid binding proteins. EMBO J: 1599-1604, 1987.

12. Schlaepfer DD, Mehlman T, Burgess WH and Haigler HT: Structural and functional characterization of endonexin II, a calcium- and phospholipids-binding protein. Proc Natl Acad Sci USA 84: 6078-6082, 1987.

13. Blackwell GJ, Carnuccio R, DiRosa M, Flower RJ, Parente L and Persico P: Macrocortin, a polypeptide causing the anti-phospholipase effects of glucocorticoid. Nature 287: 147-149, 1980.

14. Flower RJ, Wood JN and Parente L: Macrocortin and the mechanism of action of the glucocorticoids. Adv Inflam Res 7: 61-70, 1984.

15. Creutz CE, Zakas WJ, Hamman HC, et al: Identification of chromaffin granule-binding proteins. J Biol Chem 262: 1860-1868, 1987.

16. Khanna NC, Tokuda M and Waisman DM: Purification of three forms of lipocortin from bovine lung. Cell Calcium 8: 217-228, 1987.

17. Raynal P and Pollard HB: Annexins; the problem of assessing the biological role for a gene family of multifunctional calciumand phospholipid-binding proteins. Biochim Biophys Acta 1197: 63-93, 1994.

18. Gerke V and Moss SE: Annexins; from structure to function. Physiol Rev 82: 331-371, 2002.

19. Waisman DM: Annexin II tetramer; structure and function. Mol Cell Biochem 149: 301-322, 1995.

20. Gerke V and Weber K: Identity of p36K phosphorylated upon Rous sarcoma virus transformation with a protein purified from brush borders; calcium-dependent binding to non-erythroid spectrin and F-actin. EMBO J: 227-233, 1984.

21. Gould KL, Woodgett JR, Isacke CM and Hunter T: The proteintyrosine kinase substrate p36 is also a substrate for protein kinase C in vitro and in vivo. Mol Cell Biol 6: 2738-2744, 1986.

22. Biener Y, Feinstein R, Mayak M, Kaburagi Y, Kadowaki T and Zick Y: Annexin II is a novel player in insulin signal transduction. Possible association between annexin II phosphorylation and insulin receptor internalization. J Biol Chem 271: 29489-29496, 1996.

23. Jiang Y, Chan JL, Zong CS and Wang LH: Effect of tyrosine mutations on the kinase activity and transforming potential of an oncogenic human insulin-like growth factor I receptor. J Biol Chem 271: 160-167, 1996.

24. Brambilla R, Zippel R, Sturani E, Morello L, Peres A and Alberghina L: Characterization of the tyrosine phosphorylation of calpactin I (annexin II) induced by platelet derived growth factor. Biochem J 278: 447-452, 1991

25. Erickson E and Erickson RL: Identification of a cellular protein substrate phosphorylated by the avian sarcoma virus transforming gene product. Cell 21: 829-836, 1980.

26. Paciucci R, Tora M, Díaz VM and Real FX: The plasminogen activator system in pancreas cancer: role of t-PA in the invasive potential in vitro. Oncogene 16: 625-633, 1998.

27. Emoto K, Sawada H, Yamada Y, et al: Annexin II overexpression is correlated with poor prognosis in human gastric carcinoma. Anticancer Res 21: 1339-1345, 2001.

28. Guzmán-Aránguez A, Olmo N, Turnay J, et al: Differentiation of human colon adenocarcinoma cells alters the expression and intracellular localization of annexins A1, A2, and A5. J Cell Biochem 94: 178-193, 2005.

29. Reeves SA, Chavez-Kappel C, Davis R, Rosenblum M and Israel MA: Developmental regulation of annexin II (Lipocortin 2) in human brain and expression in high grade glioma. Cancer Res 52: 6871-6876, 1992 .

30. Liu J, Rothermund CA, Ayala-Sanmartin J and Vishwanatha JK: Nuclear annexin II negatively regulates growth of LNCaP cells and substitution of ser 11 and 25 to glu prevents nucleocytoplasmic shuttling of annexin II. BMC Biochem 9: 4-10, 2003. 
31. Chetcuti A, Margan SH, Russell P, et al: Loss of Annexin II heavy and light chains in prostate cancer and its precursors. Cancer Res 61: 6331-6334, 2001.

32. Liu JW, Shen JJ, Tanzillo-Swarts A, et al: Annexin II expression is reduced or lost in prostate cancer cells and its re-expression inhibits prostate cancer cell migration. Oncogene 22: 1475-1485, 2003.

33. Zhang X, Zhi HY, Zhang J, et al: Expression of annexin II in human esophageal squamous cell carcinoma. Zhonghua Zhong Liu Za Zhi 25: 353-355, 2003.

34. Rodrigo Tapia JP, Pena Alonso E, García-Pedrero JM, et al: Annexin A2 expression in head and neck squamous cell carcinoma. Acta Otorrinolaringol Esp 58: 257-262, 2007.

35. Pena-Alonso E, Rodrigo JP, Parra IC, et al: Annexin A2 localizes to the basal epithelial layer and is down-regulated in dysplasia and head and neck squamous cell carcinoma. Cancer Lett 263: 89-98, 2008.

36. Masaki T, Tokuda M, Fujimura T, et al: Involvement of annexin I and annexin II in hepatocyte proliferation: can annexins I and II be markers for proliferative hepatocytes? Hepatology 20: 425-435, 1994.

37. Desmet VJ, Gerber M, Hoofnagle JH, Manns M and Scheuwer PJ: Classification of chronic hepatitis: diagnosis, grading, and staging. Hepatology 19: 1513-1520, 1994.

38. International Working Party: Terminology of nodular hepatocellular lesions. Hepatology 22: 983-993, 1995.

39. Laemmli UK: Cleavage of structural proteins during the assembly of the head of bacteriophage T4. Nature 227: 680-685, 1970.

40. Towbin H, Stadhelin T and Gordon J: Electrophoretic transfer of proteins from poly-acrylamide gels to nitrocellulose sheets: procedure and some applications. Proc Natl Acad Sci USA 76: 4350-4354, 1979

41. Masaki T, Okada M, Shiratori Y, et al: pp60 ${ }^{\text {c-src }}$ activation in hepatocellular carcinoma of humans and LEC rats. Hepatology 27: $1257-1264,1998$

42. Masaki T, Shiratori Y, Rengifo W, et al: Cyclins and cyclindependent kinases: comparative study of hepatocellular carcinoma versus cirrhosis. Hepatology 37: 534-543, 2003

43. Li JQ, Kubo A, Wu F, et al: Cyclin B1, unlike cyclin G1, increases significantly during colorectal carcinogenesis and during later metastasis to lymph nodes. Int J Oncol 22: 1101-1110, 2003.

44. Yuji J, Masaki T, Yoshida S, et al: Identification of p46 Shc expressed in the nuclei of hepatocytes with high proliferating activity: study of regenerating rat liver. Int J Mol Med 13: 721-728, 2004.

45. Kita Y, Masaki T, Funakoshi F, et al: Expression of G1 phaserelated cell cycle molecules in naturally developing hepatocellular carcinoma of Long-Evans Cinnamon rats. Int J Oncol 24: 1205-1211, 2004.

46. Li JQ, Wu F, Masaki T, et al: Correlation of Skp2 with carcinogenesis, invasion, metastasis, and prognosis in colorectal tumors. Int J Oncol 25: 87-95, 2004.
47. Morishita A, Masaki T, Yoshiji H, et al: Reduced expression of cell cycle regulator p18(INK4C) in human hepatocellular carcinoma. Hepatology 40: 77-86, 2004.

48. Yoshida S, Masaki T, Feng H, et al: Enhanced expression of adaptor molecule p46 Shc in nuclei of hepatocellular carcinoma cells: study of LEC rats. Int J Oncol 25: 1089-1096, 2004.

49. Masaki T, Tokuda M, Yoshida S, et al: Comparison study of the expressions of myristoylated alanine-rich $\mathrm{C}$ kinase substrate in hepatocellular carcinoma, liver cirrhosis, chronic hepatitis, and normal liver. Int J Oncol 26: 661-671, 2005.

50. Yukimasa S, Masaki T, Yoshida S, et al: Enhanced expression of p46 Shc in the nucleus and p52 Shc in the cytoplasm of human gastric cancer. Int J Oncol 26: 905-911, 2005.

51. Nonomura T, Masaki T, Morishita A, et al: Identification of c-Yes expression in the nuclei of hepatocellular carcinoma cells: Involvement in the early stages of hepatocarcinogenesis. Int $\mathbf{J}$ Oncol 30: 105-111, 2007.

52. Igarashi K, Masaki T, Shiratori Y, et al: Activation of cyclin D1-related kinase in human lung adenocarcinoma. Br J Cancer 81: 705-711, 1999.

53. Masaki T, Tokuda M, Ohnishi M, et al: Enhanced expression of the protein kinase substrate annexin in human hepatocellular carcinoma. Hepatology 24: 72-81, 1996.

54. Frohlich M, Motté P, Galvin K, Takahashi H, Wands J and Ozturk M: Enhanced expression of the protein kinase substrate p36 in human hepatocellular carcinoma. Mol Cell Biol 10: 3216-3223, 1990.

55. Sharma MR, Koltowski L, Ownbey RT, Tuszynski GP and Sharma MC: Angiogenesis-associated protein annexin II in breast cancer: selective expression in invasive breast cancer and contribution to tumor invasion and progression. Exp Mol Pathol 81: 146-156, 2006.

56. Cole SP, Pinkoski MJ, Bhardwaj G and Deeley RG: Elevated expression of annexin II (lipocortin II, p36) in a multidrug resistant small cell lung cancer cell line. Br J Cancer 65: 498-502, 1992.

57. Chiang Y, Davis RG and Vishwanatha JK: Altered expression of annexin II in_human B-cell lymphoma cell lines. Biochim Biophys Acta 1313: 295-301, 1996.

58. Menell JS, Cesarman GM, Jacovina AT, McLaughlin MA, Lev E and Hajjar KA: Annexin II and bleeding in acute promyelocytic leukemia. N Engl J Med 340: 994-1004, 1999.

59. Emoto K, Yamada Y, Sawada H, et al: Annexin II overexpression correlates with stromal tenascin-C overexpression: a prognostic marker in colorectal carcinoma. Cancer 92: 994-1026, 2001.

60. Hunter T and Sefton BM: Transforming gene product of Rous sarcoma virus phosphorylates tyrosine. Proc Natl Acad Sci USA 77: $1311-1315,1980$.

61. Ohgi T, Masaki T, Nakai S, et al: Expression of p33(ING1) in hepatocellular carcinoma: relationships to tumour differentiation and cyclin E kinase activity. Scand J Gastroenterol 37: 1440-1448, 2002. 